\title{
Increasing Access and Quality of Behavior-Analytic Services for the Latinx Population
}

\author{
Mariela Castro-Hostetler ${ }^{1}$ (D) - Ashley E. Greenwald ${ }^{2} \cdot$ Matthew Lewon $^{1}$
}

Accepted: 10 June 2021 / Published online: 13 September 2021

(C) Association for Behavior Analysis International 2021

\begin{abstract}
Latinxs are the largest minority group in the United States, making up approximately $18 \%$ of the total population. Although there is a critical need for the behavioral health care system, including behavior analysts, to provide services to support the needs of the Latinx community, access to quality behavioral and mental health services continues to be lacking for the Black, Indigenous, and people of color populations. This article highlights some of the cultural and language factors that should be considered by behavior-analytic providers who have a shared responsibility to make culturally and linguistically appropriate services available to this population. Additionally, recommendations for systemic action across service providers, professional organizations, behavior-analytic training programs, and researchers are suggested to address these barriers. Recommendations for bringing about this systemic change are suggested across three domains: (a) increasing diversity in the behavior-analytic workforce, (b) enhancing training in cultural- and language-related issues, and (c) conducting research on cultural and language adaptations to behavior-analytic evidence-based treatments.
\end{abstract}

Keywords Latinx $\cdot$ behavioral health services $\cdot$ cultural diversity $\cdot$ multilingual diversity social validity

Latinxs constitute the largest minority group in the United States, currently making up approximately $18 \%$ of the total U.S. population (U.S. Census Bureau, 2018). For the purposes of this article, we will use the term Latinx to refer to people of Latin American origin or descent (this term is used as a gender-neutral or nonbinary alternative to Latino or Latina), which in turn has been defined as individuals of "Cuban, Mexican, Puerto Rican, South or Central American, or other Spanish culture or origin, regardless

Mariela Castro-Hostetler

Marielacastro@nevada.unr.edu

1 Department of Psychology, University of Nevada, MS 296, 1664 North Virginia Street, Reno, NV 89557, USA

2 University of Nevada, Reno, NV, USA 
of race" (U.S. Census Bureau, 2018). Although the definition of who may be considered Latinx has evolved over the years, it is now most often used as a nonbinary term to define an individual's ethnicity and not race (Steinmetz, 2018). ${ }^{1}$

One subpopulation that is often overlooked in this categorization is Black Latinxs (or Afro-Latinxs). According to the Pew Research Center (2016), one quarter of all U.S. Latinxs self-identify as Black Latinx or Afro-Caribbean or of African descent with roots in Latin America, thereby indicating that there may be several subcultures within certain larger cultural groups (López \& Gonzalez-Barrera, 2016). Among Latinx subgroups in 2010, Mexicans ranked as the largest subgroup (64\%), followed by Puerto Ricans (9.4\%), Salvadorans (3.8\%), Cubans (3.7\%), Dominicans (3.1\%), Guatemalans (2.3\%), and Latinxs from other areas across Latin America (13.7\%; Motel $\&$ Patten, 2012). The Census Bureau (2018) has projected that self-identifying Latinxs will compose $28 \%$ of the total U.S. population by 2060 (Vespa et al., 2020).

With the ongoing increase in the Latinx population, it is expected that the percentage of Latinx individuals seeking behavioral and mental health services will also continue to increase. There is a critical need for the behavioral health care system, including behavior analysts, to be prepared and organized to support the Latinx community. Nevertheless, the quality of and access to behavioral and mental health services are often lacking for the Black, Indigenous, and people of color (BIPOC) populations (Bishop-Fitzpatrick \& Kind, 2017; Cabassa et al., 2012; Dahne et al., 2019; Institute of Medicine, 2003). Research suggests that at present, the majority of Latinx children and families who require mental health services do not receive them (Alegría et al., 2008; Hines et al., 2017; C. Lopez et al., 2008; Rastogi et al., 2012). Similar to other marginalized groups, Latinx families are less likely to seek and receive behavioral health services than their White counterparts, resulting in higher rates of unmet needs (Flores, \& Committee on Pediatric Research 2010). BIPOC families are also more likely to be misdiagnosed and undertreated and to receive access to services for their children later than non-BIPOC families (Chapa, 2004; S. Magaña et al., 2013; Rosales et al., 2021). The COVID-19 pandemic has brought these social and racial disparities in health care access into even sharper relief. The Centers for Disease Control and Prevention (2021) report that the pandemic "has unequally affected many racial and ethnic minority groups, putting them more at risk of getting sick and dying from COVID-19” (p. 1). Similarly, access to psychological and social services has been reduced for all individuals during the pandemic (Frederick et al., 2021), and this general trend appears to have disproportionately affected BIPOC communities (Valenzuela et al., 2020).

\section{Responsibility of Behavior Analysts}

Like other human service professionals, behavior analysts increasingly acknowledge the importance of diversity and equity in all aspects of the field (Conners et al., 2019; Wang et al., 2019; Zarcone et al., 2019). The term equity will be used here and

\footnotetext{
${ }^{1}$ According to a recent Pew Research Center survey, 23\% of Hispanic respondents have heard the term Latinx, but only $3 \%$ reported using it to describe themselves; $61 \%$ and $29 \%$ reported preferring the terms Hispanic or Latino, respectively (Noe-Bustamante et al., 2020). The term Latinx is used in this article as it is currently considered to be a more progressive and inclusive identifier (Scharrón-del Rio \& Aja, 2020).
} 
throughout this article to refer to equal access and use of services by individuals of equal need, regardless of social or racial background (Macias et al., 2020). Behavior analysts have a shared duty to (a) ensure equity in access to quality services for people of all ages, genders, races, and cultures and (b) provide services that are sensitive to the linguistic and cultural circumstances of their consumers. One important source of these obligations is the professional guidelines laid out by the Behavior Analyst Certification Board (BACB), which governs practice provided by behavior analysts. Two subsections of the current Professional and Ethical Compliance Code for Behavior Analysts (BACB, 2014) under Section 1.05 (Professional and Scientific Relationships) are directly relevant to the ethical provision of services to Latinx consumers:

1.05 (b) When behavior analysts provide behavior-analytic services, they use language that is fully understandable to the recipient of those services while remaining conceptually systematic with the profession of behavior analysis. They provide appropriate information prior to service delivery about the nature of such services and appropriate information later about results and conclusions.

1.05 (c) Where differences of age, gender, race, culture, ethnicity, national origin, religion, sexual orientation, disability, language, or socioeconomic status significantly affect behavior analysts' work concerning particular individuals or groups, behavior analysts obtain the training, experience, consultation, and/or supervision necessary to ensure the competence of their services, or they make appropriate referrals.

Encouragingly, the BACB recently published significant revisions to the discipline's ethical code, and the Ethics Code for Behavior Analysts (BACB, 2020a) will supersede the Professional and Ethical Compliance Code for Behavior Analysts (BACB, 2016) beginning in January 2022. The most relevant changes regarding cultural inclusivity can be found in Sections 1.07 (Cultural Responsiveness and Diversity), 1.08 (Nondiscrimination), 1.10 (Awareness of Personal Biases and Challenges), and 4.07 (Incorporating and Addressing Diversity). These sections clarify the specific responsibilities of behavior analysts in serving individuals with different needs and backgrounds. In particular, more explicit language has been added pertaining to behavior analysts' responsibilities to engage in professional development activities with respect to cultural responsiveness and diversity. The new guidelines also specifically require behavior analysts to examine their biases along with those of their trainees/supervisees and take steps to address these in providing services to individuals with different needs.

Social validity is an additional reason why behavior analysts should be concerned with developing and providing linguistically and culturally sensitive treatments to the Latinx population (Common \& Lane, 2017; Kazdin, 1977; Wolf, 1978). Social validity is the extent to which treatment goals, methods, and outcomes are deemed acceptable or important by integral team members. Integral team members may be considered to include recipients of service, their families and caregivers, and their communities. A keystone of applied behavior analysis is the use of the principles of learning to bring about socially significant behavior change (Baer et al., 1968), and social validity is an increasingly important metric for evaluating the importance of treatment outcomes (Baer et al., 1987). Social validity measures may be viewed as a "check" on service providers' biases (which arise from their enculturation) as to what constitutes 
acceptable and meaningful treatment goals, methods, and outcomes while providing treatment to individuals from different cultural backgrounds (Kleeck, 1994). In supporting people of various cultural backgrounds, the ethical responsibility of the behavior analyst includes identifying unique factors that contribute to an individual's quality of life (Schalock et al., 2008) and avoiding what has been described as a "colonial" service model, wherein the authority and values of a service provider are the primary source of decisions regarding treatment goals and approaches, in the absence of input from the consumers of these services (Fawcett, 1991). The model of social validity advanced by Fawcett (1991) and further enhanced by the person-centered planning movement (Claes et al., 2010) places responsibility on service providers to incorporate consumer values, goals, and preferences into each aspect of a support plan.

As a subjective measure of "consumer satisfaction" and as a prescribed professional ethical responsibility, social validity is an important outcome in its own right. However, social validity is also related pragmatically to the probability of treatment success or efficacy. The majority of behavior analysts do not work in isolation; they typically provide their services as members of teams of professionals and must enlist the support of integral team members such as families and teachers in order to promote the establishment, generalization, and maintenance of behavior change. Interventions are most likely to be effective if they are deemed socially valid because team members are more likely to approve, adopt, and follow through with them (Common \& Lane, 2017; Larson et al., 2020; Strain et al., 2012). Providing treatment options that are sensitive to the cultural and linguistic needs of Latinx individuals may therefore be considered an important factor in determining the likelihood of treatment success above and beyond ethical obligations.

\section{Barriers to Accessing/Using Behavioral Health Services}

Latinx individuals represent an important and growing part of the U.S. population, but they continue to face significant barriers in accessing and using behavioral health services, including those offered by behavior analysts. Some of these barriers are related to overarching political, legal, and economic issues (e.g., the important issue of immigration processes and immigration status; Becerra et al., 2015; Chen \& Vargas-Bustamante, 2011; Kullgren, 2003; Torres \& Rollock, 2004). Though behavior analysts, like other human services professionals, may be seen to have an ethical responsibility to act to address these society-level issues relevant to their client communities through advocacy and activism as citizens (Bhattarai et al., 2020), this article will focus on the barriers that may be addressed by behavior analysts in their roles as service providers. There are several domains in which behavior analysts in their professional capacities have both the opportunity and the responsibility to take action to minimize barriers to service and develop interventions that are tailored to the needs of Latinx consumers. Awareness of the barriers faced by Latinx consumers is an important first step in this regard.

\section{Language}

Language is a major barrier that many Latinx families confront in accessing behavioral health services (August et al., 2011). The term limited English proficiency (n.d.). (LEP) describes "individuals who do not speak English as a primary language and who have a 
limited ability to read, speak, write or speak, or understand English" (LEP.gov, n.d., para. 1). According to the Migration Policy Institute (2013), approximately 63\% of the LEP population in the United States are Latinxs (Zong \& Batalova, 2015). LEP affects the ability to obtain health care services, resulting in less care and treatment for those struggling with behavioral health needs (Ornelas \& Perreira, 2011; Zuckerman et al., 2017). The issue of LEP is multifold, bringing difficulties both in terms of the Latinxs trying to access services and the providers striving to meet the needs of these families (Kornack et al., 2019).

When a family member receives an initial diagnosis, language plays a crucial role in communicating the implications of the diagnosis and providing guidance regarding treatment options. LEP families are more likely to be misinformed regarding the diagnoses their loved ones receive (Zuckerman et al., 2017). Furthermore, written information regarding services or resources is not often available in languages other than English (Dennison et al., 2019; Wang et al., 2019).

Once treatment is initiated, other challenges related to language may arise. Communication facilitates the presentation of information, expectations, and treatment guidelines from providers (Hansen \& Aranda, 2012). Unsurprisingly, communication (and by proxy, treatment) is hindered when there is a mismatch between the languages spoken by providers and consumers of behavioral health services (Kouyoumdjian et al., 2003). From providers' perspectives, communication difficulties with LEP families may be perceived as a family's lack of engagement or commitment to receiving services (August et al., 2011; Snowden et al., 2006). From the families' perspectives, they may be unable to communicate what they observe during treatment and how they feel about how treatment is proceeding (Lagomasino et al., 2005; D. Magaña, 2020).

Language and communication also play a significant role in developing and maintaining a good therapeutic relationship between families and providers. Good therapeutic relationships are one aspect of social validity, and families are more likely to initiate and continue treatment with providers with whom they have a strong working relationship (Ferguson \& Candib, 2002). Research also indicates that Latinxs often prefer to receive services from someone who speaks their native language (Peters et al., 2014). Latinxs who communicate primarily in Spanish report being more dissatisfied with care when their care providers are non-Spanish speaking (Alegría et al., 2008; Fernandez et al., 2011; Morales et al., 1999).

Challenges related to language can in some circumstances be circumvented by the use of an interpreter, but this is a less-than-ideal solution. One reason for this is that interpreters are not always present/available when a practitioner needs to communicate with family members. Another is that it may be difficult to ensure that the meaning of a practitioner's words is adequately translated into listeners' language, especially when interpreters are not behavior analysts and are tasked with communicating the meaning of technical behavior-analytic terms (Brodhead et al., 2018; Dennison et al., 2019).

\section{Culture}

The cultural assumptions and values held by individuals profoundly affect decisions regarding whether or not to pursue treatment; the selection of or preference for treatment providers, methods, and goals; and the continuation of services once initiated (Buzhardt et al., 2016; T. B. Smith et al., 2011). Consumers also prefer therapists who 
share their cultural backgrounds (Cabral \& Smith, 2011). Cultural practices and beliefs may be considered barriers if they contribute to preventing individuals of a particular group from accessing behavioral health services that are provided by therapists from other backgrounds. Behavior analysts have the responsibility to devise treatment strategies that accommodate the cultural values of all consumers (Brodhead, 2019; Fong et al., 2016; Miller et al., 2019; Rosenberg \& Schwartz, 2019; Wright, 2019).

Although subgroups within the larger group identified as Latinx have different cultural practices and values, they share many cultural commonalities (Garcia-Preto, 2005). As one example, research suggests that collectivist values are more common among Latinx groups than those that emphasize individuality (Sue \& Sue, 2016). In the context of families, this has taken the form of what has been called familismo (Paniagua, 1998). Familismo refers to the importance of strong family loyalty, closeness, and contributions to the well-being of the nuclear and extended family (Cauce \& Domenech-Rodriguez, 2002; Falicov, 1998; Guilamo-Ramos et al., 2007; Parsai et al., 2009). It has also been described in terms of obligation to family members across generations, regardless of the length of time one has resided in the United States (Harwood et al., 2002; Santiago-Rivera, 2003). Familismo manifests itself in cultural practices that are distinct from those of many non-Latinx families, including multigenerational households and the collective rearing of children. Failure to tailor treatment protocols to Latinx family circumstances can prevent Latinx consumers from seeking services or make them more likely to discontinue receiving services due to a lack of contextual fit (Angell et al., 2016; Rosales \& Calvo, 2017).

Another cultural characteristic common to many Latinx communities is the belief in faithbased supports and alternatives to evidence-based practices (Sue \& Sue, 2016). This is related to the value of fatalismo. Fatalismo is the belief that life's misfortunes are inevitable and that people should be resigned to accept their fates (Abraído-Lanza et al., 2015; Anastasia \& Bridges, 2015; Flores, 2000). Fatalismo is often associated with attributing explanations for events to a higher power, destiny, or luck (Añez et al., 2005; Flórez et al., 2009). Fatalismo can contribute to a generally negative attitude toward medical and preventative services or a reluctance to use such services (Abraído-Lanza et al., 2015; Espinosa de los Monteros \& Gallo, 2011; Kouyoumdjian et al., 2003; Schwab et al., 1994). For this reason, it may be more difficult for Latinx families to place their trust in service providers, and this may be exacerbated by scientifically oriented providers' skeptical or negative views of spirituality-based approaches (Ecklund \& Long, 2011). However, acknowledging fatalismo and modifying treatment approaches in light of this value have been shown to benefit therapeutic relationships (Añez et al., 2005).

The previous discussion does not constitute an exhaustive list of the barriers that Latinx consumers face in accessing behavioral services, but they represent perhaps the most significant ones. Some ways in which behavior analysts may contribute to addressing these barriers in their capacities as professionals are presented in the following sections.

\section{Increasing Diversity Among Behavior Analysts}

One way to increase access to behavior-analytic services for Latinx families is to increase diversity in the field at large, particularly by increasing the number of 
practicing Latinx behavior analysts. It is generally acknowledged that there is not enough diversity among behavior-analytic practitioners, and there is a continued need to work toward solutions for promoting diversity (Beaulieu et al., 2019; Beene, 2019; Conners et al., 2019; Szabo, 2020; Zarcone et al., 2019).

Increasing diversity among behavior-analytic practitioners and researchers has the potential to benefit the field and consumers of its services in many ways. With respect to treatment, more diversity means that there are more behavior analysts familiar with different cultures and able to speak different languages, thereby increasing access to culturally sensitive services for consumers who face difficulties in obtaining them. More diversity among behavior analysts would also enhance the ability to engage in cultural cross-training among colleagues. BACB guidelines dictate that those who do not have expertise working with a particular population must acquire it before providing services to that population (BACB, 2014). Increasing diversity would make it easier for the next generation of behavior analysts to receive this training. In a more general sense, diverse workforces bring different perspectives to bear on problems, thus helping to solve them more creatively and effectively (Crosby et al., 2003; Rogers \& Molina, 2003).

It is relatively easy to call for increased diversity and point out its benefits, but it is more difficult to propose and evaluate effective strategies to achieve this. The issue is systemic and requires action on the part of several classes of organizations. The following subsections are considerations that various organizations may adopt to enhance cultural diversity and inclusivity.

\section{Service Provider Organizations}

Behavior-analytic service provider organizations have both a responsibility and a fundamental role to play in promoting diversity among behavior analysts. The responsibility derives from the aforementioned professional guidelines regarding the obligation to deliver culturally sensitive services to all consumers, regardless of culture, race, age, gender, or language. Service organizations should consider the role of cultural diversity as it pertains to both organizational leadership and the direct support staff responsible for delivering interventions with individual clients.

Registered Behavior Technicians (RBTs) and Board Certified Assistant Behavior Analysts (BCaBAs) often make up a large portion of the staff and provide the bulk of direct service hours in behavior-analytic service provider organizations. Prioritizing diversity in recruitment for these positions can allow an organization to serve the needs of a wider range of families. RBT training and ongoing supervision may also serve as many individuals' first point of contact with behavior analysis, thereby making it more likely that they go on to pursue graduate training. Wang et al. (2019) recommended prioritizing the recruitment of RBTs who are multilingual or of different cultural backgrounds at recruiting events. Organizations may also offer training classes and informational sessions in Latinx communities to contact young professionals exploring career paths. Recruitment may be fostered through collaboration with other Latinx professionals, schools, churches, cultural centers, or other nonprofit organizations.

Provider organizations also have the opportunity to advance diversity when they hire Board Certified Behavior Analysts (BCBAs) into positions of clinical and organizational leadership. BCBAs proficient in the language and knowledgeable about the 
cultural values of Latinx consumers are more likely to devise language- and culturally sensitive treatment strategies, and they may provide valuable training in these areas to their RBT supervisees. As noted previously, this can contribute in important ways to the social validity of an organization's services. Increasing the number of Latinx behavior analysts in service organizations should also be accompanied by opportunities for Latinxs to assume positions of leadership. Leaders play a fundamental role in determining organizational culture (Esquierdo-Leal \& Houmanfar, 2020), but it is well documented that BIPOC individuals have fewer leadership opportunities compared to their non-BIPOC counterparts with similar skill sets (Cirincione-Ulezi, 2020; Makino \& Oliver, 2019). The hiring of Latinx individuals in positions of organizational leadership can advance diversity and the retention and advancement of Latinx employees by contributing to a workplace culture that is inclusive.

The BACB has recently begun publishing demographic data for certificants who report this information (BACB, 2020b). At the time of this writing, Latinxs are overrepresented relative to their representation in the general population at the BCaBA and RBT levels of certification (31.9\% and $29.3 \%$ of certificants, respectively). However, they are notably underrepresented at the BCBA and BCBA-D (doctoral-level BCBA) levels of certification (just $9.8 \%$ of certificants). Because only approximately half of BCBAs/BCBA-Ds and BCaBAs and only about a third of RBTs have reported this information, it is possible that these data are not fully representative, and these data provide only a small glimpse into the larger issue of Latinx representation in behavior analysis. Nevertheless, they are a trend worth noting. It is encouraging that Latinxs appear to be well represented at the RBT and BCaBA levels of certification, but these data suggest that simply recruiting and training $\mathrm{BCaBA}-$ and $\mathrm{RBT}$ level employees are not sufficient to increase their representation in positions of leadership. One potential way to address this is to increase efforts to actively recruit Latinxs into graduate training programs.

\section{Recruitment and Retention of Graduate Students}

The recruitment and retention of students in graduate training programs in behavior analysis are important contributors to diversity in the field, especially in terms of leadership. If more Latinxs receive graduate training in behavior analysis, there are bound to be more Latinx behavior-analytic business owners, more Latinx BCBA-level practitioners to provide culturally sensitive treatment and training to staff in service organizations, and more Latinx candidates for behavior-analytic academic faculty positions. The apparently large number of Latinxs working as BCaBAs and RBTs suggests that service provider organizations may be one target for recruitment efforts.

Recruitment of Latinx graduate students may also be facilitated by exposing students to behavior analysis and recruiting them during their undergraduate education. Providing opportunities for Latinx undergraduate students to come into contact with the field early in their education may make it more likely that they go on to seek behavioranalytic clinical experience or graduate training. This could be achieved in several ways. First, the Association for Behavior Analysis International (ABAI) has recently begun accrediting undergraduate programs in behavior analysis, though there are only two such programs at the time of this writing. If behavior-analytic faculty are able to obtain university support for accredited undergraduate programs in behavior analysis, it 
would likely serve to attract a wider range of students to the field. Other methods of recruitment may include establishing undergraduate behavior analysis clubs and offering behavior-analytic research opportunities for undergraduates. Graduate programs could also establish recruitment initiatives aimed at attracting BIPOC students. As an example, the University of Michigan's psychology program created a graduate recruitment initiative for students from educational, cultural, or geographic backgrounds that are underrepresented in graduate training programs in psychology (University of Michigan, 2020). Potential applicants from these groups were offered workshops and panel discussions to help prepare them for the admissions process and allow them to meet faculty and students in the program.

Research from related fields has suggested that although student recruitment is perhaps the most important factor in increasing diversity, retention of graduate students is another important consideration (Callahan et al., 2018). Rogers and Molina (2006) described the recruitment and retention strategies used by 11 departments and programs considered to be making exemplary efforts to attract and retain BIPOC students. The strategies most consistently used in these programs included (a) engaging current BIPOC faculty and students in recruitment activities, (b) offering attractive financial aid packages, and (c) having faculty members make personal contacts with prospective students.

Related to these, mentorship is known to be an important factor in student retention (Alcocer \& Martinez, 2018; Fong et al., 2017; Kuh, 2012). A mentor-mentee relationship framework can allow the creation of professional expectations and the establishment of a personal and collaborative relationship. Furthermore, mentoring can be an effective tool that can further impact overall achievement in terms of outcomes and increasing retention in graduate programs (Alcocer \& Martinez, 2018; HollowayFriesen, 2019; Klinge, 2015). In particular, mentorship by established BIPOC faculty can help students navigate academic culture, develop strategies for overcoming barriers related to race, and create road maps for desired career goals (Alegría et al., 2019; Cirincione-Ulezi, 2020; Fries-Britt et al., 2011). Hinton et al. (2020) provided some recommendations for how mentors can have a positive influence and contribute to quality, effective mentoring for BIPOC students. One example is to create an environment where factors such as implicit and unconscious bias are discussed and acknowledged (Alegría et al., 2019; Hinton et al., 2020). The ability to discuss difficult topics can help BIPOC students and junior faculty build strategies for professional development that help lead to leadership positions (Alegría et al., 2019).

\section{Academic Faculty}

Diversity among academic faculty improves diversity in a field more broadly by enhancing recruitment, retention, and mentorship of BIPOC students and junior faculty (Fong et al., 2017; Llamas et al., 2019; Najdowski et al., 2021). Faculty diversity also enhances training for all students in areas related to multiculturalism. As such, increasing the number of Latinxs in academia may be seen as an important factor in increasing access to culturally sensitive behavior-analytic services for Latinx families.

Although there has been an increase in diversity among students at universities, diversity in the professoriate has not kept pace with this trend (Finkelstein et al., 2016; Sensoy \& DiAngelo, 2017). These differences are most pronounced in the STEM fields 
but are also present in the social sciences and humanities (Finkelstein et al., 2016; Hill et al., 2010). To meet the diversity goals of most higher education institutions today, BIPOC faculty need to be hired at an increased rate (Bensimon et al., 2016; Marschke et al., 2007). The demographic profile of behavior analysis faculty is at present unknown, but Latinxs represented just $4.7 \%$ of full-time faculty at universities in the United States in 2016 (U.S. Department of Education, 2016).

The barriers to increasing diversity in the academy are complex, and solutions can be difficult to identify and implement. Most institutions explicitly recognize the value of diversity in mission and policy statements, and many incorporate diversity criteria or guidelines when conducting faculty searches and hires (Sensoy \& DiAngelo, 2017). Nevertheless, there remain significant barriers to achieving true equity in faculty hiring. One of these has been described as the "pipeline problem," which refers to a real or perceived lack of qualified BIPOC candidates for academic appointments (Griffin, 2019; Patel, 2015). Some have argued that the hiring of BIPOC scholars in certain academic institutions is impeded by a lack of qualified BIPOC candidates, as well as the difficulty in retaining these individuals, as they tend to attract lucrative offers from more prestigious institutions (Griffin, 2019). Other barriers to diversity in hiring faculty include how and where job advertisements are announced, disparity and bias in the evaluation of BIPOC candidates during the hiring process, and the retention of BIPOC faculty once hired (Bhalla, 2019; O’Meara et al., 2020; Sensoy \& DiAngelo, 2017; D. G. Smith et al., 2004).

These issues are difficult to address, and more research on the efficacy of strategies designed to overcome them is needed to move from simply valuing diversity to actually increasing diversity among higher education faculty (Dumas-Hines et al., 2001). The strategies considered in the preceding sections regarding the hiring of Latinx RBTs and the recruitment/retention of Latinx graduate students may aid in mitigating this issue to some extent by increasing the number of Latinxs entering academia. In addition to university-level efforts, ABAI oversees accreditation for behavior-analytic training programs and could require individual behavior analysis programs to demonstrate efforts to recruit BIPOC faculty as a part of the accreditation process. In the absence of such requirements, individual programs could commit to prioritizing the hiring of BIPOC faculty by taking explicit measures such that (a) job announcements are posted in ways that are most likely to reach BIPOC candidates, (b) bias is minimized in the evaluation of applications and interviews, and (c) once hired, BIPOC faculty have access to mentorship, support, and resources that will contribute to their retention.

\section{Professional Organizations}

Professional organizations such as ABAI and its regional affiliates and the Association of Professional Behavior Analysts may promote diversity among behavior analysts in other ways (Wang et al., 2019), most notably in managing scholarly journals and organizing conferences. Journals are important forums for dissemination and discussion within a field, and it is a healthy sign that there has been much recent discussion regarding diversity (Beaulieu et al., 2019; Fong et al., 2016; Zarcone et al., 2019), multiculturalism (Conners et al., 2019; Dennison et al., 2019), and multilingualism (Wang et al., 2019) appearing in behavior-analytic journals. Recognizing the importance of these issues is an important first step, and the next step is conducting research 
on strategies aimed at affecting positive change in the demographics of the field and in the delivery of services that are tailored to the cultural and linguistic needs of consumers of behavior-analytic services.

Conferences held by professional organizations are another way in which they may advance diversity in the field. These provide an invaluable opportunity for behavior analysts to be exposed to novel topics and network with others for purposes of support, mentorship, and collaboration. ABAI's special interest groups provide the chance for individuals to connect with others who share similar interests. These can expose Latinxs to meaningful professional experiences that may serve to keep them in the field. Professional organizations may also contribute to the promotion of diversity by offering more scholarships/grants for membership or conference attendance aimed at Latinxs and BIPOC individuals.

An encouraging recent development is the establishment of a number of organizations committed to promoting diversity by increasing the visibility of certain groups, disseminating research and information, and providing networking opportunities. These organizations include Women in Behavior Analysis, Black Applied Behavior Analysts, and the Latino Association for Behavior Analysis (LABA). LABA's current mission is "disseminating evidence-based practices and to provide support, resources, communication and networking opportunities to Latinx ABA practitioners and students" (LABA, 2019). LABA offers a fast-track intense program that focuses on mentorship and support for Latinxs (Bermudez \& Rios, 2020). In addition, LABA hosts experts in areas such as cultural humility, mentorship, and supervision to address both the needs of Latinx consumers and the careers of Latinx behavior analysts. Hosted presentations and workshops from suborganizations such as these can also serve the purpose of bringing awareness to what other fields are doing to address diversity and best practices that behavior analysis can apply.

\section{Training Behavior Analysts}

In addition to promoting diversity among behavior-analytic practitioners and academic faculty, better training in the delivery of services in multicultural and multilinguistic contexts may reduce barriers and increase the efficacy of services available to Latinx consumers. Behavior analysts are increasingly acknowledging the importance and need for more training in these domains (Beaulieu et al., 2019; Conners et al., 2019; Fong et al., 2015, 2016; Zarcone et al., 2019).

Several recent studies have provided a picture of the current state of training. Fong et al. (2015) surveyed behavior-analytic practitioners about their training experiences and opinions regarding the importance of cultural competence. The majority of respondents reported spending less than $10 \%$ of their time working with consumers from different cultural groups. Additionally, although the majority of respondents described themselves as competent in working with individuals from different cultural groups, most reported receiving on average fewer than $5 \mathrm{hr}$ of didactic and practical training in these areas. According to Beaulieu et al. (2019), behavior analysts reported that their behavior-analytic coursework included little $(47 \%)$ to no $(35 \%)$ materials aimed at diversity. Similarly, Conners et al. (2019) found that only about half of survey respondents reported receiving graduate-level fieldwork and supervision training in 
multiculturalism and diversity issues. Although there have been calls for including more didactic (Conners et al., 2019; Fong et al., 2016), as well as practical (Capell \& Sevon, 2020; Fong, 2020), training in these areas, there remain no explicit requirements for either (Capell \& Sevon, 2020; Fong et al., 2017).

To address this issue, a primary suggestion is for behavior-analytic professional organizations to incorporate explicit requirements for training in multicultural and diversity issues. This has already been accomplished in related disciplines (e.g., the American Psychological Association's accreditation guidelines for counseling, clinical, and school psychology training programs; American Psychological Association, 2002). With respect to didactic coursework, ABAI oversees accreditation of behavior-analytic educational training programs, as well as the certification of verified course sequences (VCSs) for individuals pursuing BCBA/BCaBA certification. Both sets of standards have a requirement for $45 \mathrm{hr}$ of instruction in ethics, and although some instructors in accredited/VCS programs may include curricula related to multicultural issues within this, there are no specific requirements for them to do so. The addition of explicit requirements for a certain amount of multicultural and diversity training during didactic instruction would help ensure that students are contacting this material prior to entering the workforce.

The BACB oversees the guidelines for the supervision and continuing education of certified behavior analysts and may therefore contribute to the incorporation of multicultural and diversity issues in the context of service delivery. In the recent revisions to the Ethics Code for Behavior Analysts, Section 4.07 addresses the responsibility to incorporate diversity in training and supervision activities (BACB, 2020a). One way that this may be promoted is by including specific multicultural items in the BACB Task Lists for supervision. Mandates for cultural sensitivity and competence appear in the BACB's ethics codes, but there are currently no Task List items specific to these issues (BACB, 2017). Section E of the 5th Edition Task List contains a number of general items pertaining to behavior analysts' ethical responsibility to their clients. Adding an item or two specifically related to cultural and/or language issues may make it more likely that supervisors arrange it such that this training will occur in the context of supervised experience. Additionally, the BACB might consider requiring a certain amount of continuing education units (CEUs) in diversity issues, similar to the requirements for supervision and ethics CEUs. This would ensure that practitioners continue to come into contact with current information and research in these areas following certification. Although these measures may make the necessity for training in multicultural issues more explicit, individual behavior analysts still have a responsibility as certificants to provide this training to students and supervisees.

Service provider organizations may also play an important role in training behavior analysts with respect to cultural issues. Cultural awareness and diversity may be promoted by systematically embedding training and supervision in this topic area across all aspects of the organization's operations. Fong et al. (2016) provided three general recommendations based on those initially offered by Brodhead and Higbee (2012). The first recommendation is to identify an individual within the organization who can ensure that the topic of cultural awareness is addressed. This recommendation can serve as a leadership opportunity for the aforementioned individual, as well as accountability for the organization that the topic of cultural awareness is an ongoing learning experience. The second recommendation is to incorporate cultural awareness 
training into individual supervision. This supervision can be used to discuss general topics related to cultural awareness or personal experiences that a supervisor may have encountered. The final recommendation is to incorporate cultural awareness training into group supervision and training. Conversations in a group context can serve as a platform for feedback and discussion for all staff at the organization. Although discussions surrounding culturally relevant topics can be difficult, these topics are also critical to ensure the best form of service delivery (Capell \& Sevon, 2020).

The measures discussed previously may increase behavior analysts' contact with multicultural and diversity issues during their training, but another important issue that requires more consideration is the nature of this training. Specifically, there is a need to identify the skills required in these domains and how they can be taught most effectively and efficiently. Fong and Tanaka (2013) suggested standards in cultural competence for behavior analysts, and this provides a starting point for considering what ought to be imparted to behavior analysts during their didactic and practical training. These include (a) developing an awareness of one's own cultural background and biases, (b) identifying one's own limitations in understanding cultural matters, (c) seeking additional training/consultation or referring cases out to an expert with the appropriate expertise when such limitations are identified, (d) devising treatment strategies that are sensitive to the cultural preferences of consumers, and (e) advocating for diversity in training programs and in the hiring and recruitment of behavior analysts in service organizations and training programs. Fong et al. (2016) provided detailed recommendations for how providers may develop awareness of their own cultural preferences and biases, ${ }^{2}$ identify the cultural preferences of their consumers, and use this information to make treatment decisions that are tailored both to the cultural circumstances of consumers and to the expertise of the provider. The seeming importance of self-reflection in cultural competence suggests that training in acceptance and commitment therapy (ACT) and other mindfulness-based trainings may be an important aspect of training practitioners in multicultural issues (Masuda, 2014). Selfreflection is also a fundamental aspect of cultural humility, which has been advanced as a more desirable alternative to the older idea of cultural competence (Wright, 2019). Cultural humility describes a lifelong process of self-reflection at the individual and institutional levels in order to develop respectful relationships with communities and address power imbalances between consumers and service providers (Fisher-Borne et al., 2015; Tervalon \& Murray-Garcia, 1998). Wright (2019) suggested that selfreflection is an essential skill for the development of cultural humility and in preventing one's prejudices from influencing clinical decision making.

Taken as a whole, the existing research appears to suggest that the most important skills for behavior analysts collaborating with Latinx and other BIPOC consumers in the context of a service delivery relationship are (a) frequent and ongoing self-reflection regarding one's own personal biases, skills, and power imbalances between service

\footnotetext{
2 The term bias is used here to refer to the phenomenon of responding (either overtly or covertly) to another individual, group of individuals, or their actions in a manner that is different from the way in which one might respond to others. The term bias typically has a negative connotation and in functional terms frequently involves differentially applying aversive contingencies and/or removing/withholding access to reinforcers for some individuals but not others. Relational frame theory offers a behavioral account of the role of language in bias through the verbal processes of categorization and transformation of stimulus functions (S. C. Hayes et al., 2001; Weinstein et al., 2008).
} 
providers and consumers (Wright, 2019) and (b) the incorporation of social validity assessment throughout the treatment process (Fawcett, 1991; Fong et al., 2016). With respect to the former, training for students and supervisees working with Latinx families may first take the form of arranging contingencies to promote the observation and accurate reporting of personal biases, boundaries of individual competence and knowledge, and potential power imbalances in the service provider-consumer relationship. Once this is achieved, instructors and supervisors may use these reports as an occasion to help trainees devise plans of action to address any issues or lack of skills that may interfere with the establishment of a culturally and linguistically sensitive relationship with their Latinx consumers. Teaching trainees to incorporate social validity assessment in all stages of service delivery to Latinx consumers further supports the development of cultural humility by bringing trainees into frequent contact with their consumers' needs and preferences throughout the treatment process. This may help trainees identify circumstances in which they are not meeting Latinx consumers' needs and facilitate the timely modification of behaviors targeted for change, treatment goals, or treatment methods. In a recent review of social validity assessment and reporting in intervention studies with young children in special education, Park and Blair (2019) suggested that social validity is typically not assessed frequently enough to inform intervention, and when it is assessed, not all aspects of social validity (goals, methods, and outcomes) are measured. This suggests that more explicit training in how to incorporate social validity assessment throughout the treatment process is needed, and this seems likely to enhance the sensitivity of behavior-analytic providers to the needs and preferences of their Latinx consumers.

In addition to determining if the consumer is culturally satisfied with the interventions, as often informed by social validity measurements, the behavior analyst should also be trained in person-centered planning as it relates to enhancing quality of life (QOL). The concept of QOL provides a foundation from which to create quality services that are individualized, community based, and person centered, while aligning resources with strategies that enhance personal outcomes (Schalock et al., 2008). Person-centered planning is an increasingly used approach to the creation of consumer-driven behavior support plans, particularly in the field of developmental and intellectual disabilities, with demonstrated effectiveness on personal outcomes (Claes et al., 2010). In a person-centered planning approach, the consumer's and family's voices are incorporated in the collaborative selection and identification of goals and interventions to ensure appropriate contextual and cultural relevance. In understanding these two concepts, the behavior analyst could intentionally collaborate with the consumer to include Latinx values and norms in the identified interventions while also leveraging community resources that are inherently rich in Latinx culture in order to develop a plan that is both culturally relevant and focused on enhancing the consumer's QOL.

\section{Cultural and Language Adaptations to Evidence-Based Treatments}

As noted, cultural and language issues can represent significant barriers for Latinxs in accessing behavioral health treatment. An additional concern is that the failure of service providers to acknowledge and accommodate cultural and language issues 
may compromise the efficacy of treatment provided to Latinxs. Cultural and language issues influence nearly every aspect of the diagnostic and treatment process (Barrera et al., 2013; Bernal \& Adames, 2017; Litvak \& Rue, 2020). Although the principles from which behavior-analytic treatments are derived are assumed to have generality across different groups of people, tailoring treatment to the cultural and linguistic practices of consumers and integral team members contributes to more effective treatment by allowing a more comprehensive functional analysis of consumer contexts (Alegría \& McGuire, 2003; S. C. Hayes \& Toarmino, 1995). Indeed, research from related fields (e.g., clinical psychology) has demonstrated that cultural and linguistic adaptations can increase engagement with treatment, as well as treatment efficacy (Bernal \& Adames, 2017; Domenech Rodríguez et al., 2011; Mendez \& Westerberg, 2012; T. B. Smith et al., 2011). As such, another means to increase both access to and quality of behavior-analytic services for Latinx consumers is the development of culturally and linguistically adapted treatment strategies.

Cultural adaptation has been defined generally as "the systematic modification of an evidence-based treatment (EBT) or intervention protocol to consider language, culture, and context in such a way that it is compatible with the client's cultural patterns, meanings, and values" (Bernal et al., 2009, p. 362). In the context of behavior-analytic EBTs, such modifications may include those related to (a) the behavior targeted for change, (b) the methods used to change behavior, and (c) how treatment choices are communicated to integral team members. Research on the effects of cultural and language adaptations to behavior-analytic EBTs for Latinx consumers may occur in any of these domains. For example, in the first domain, selecting target behaviors, behavior analysts may study the effects of different methods of assessing Latinx families' values, preferences, and customs on the types of target behaviors identified for intervention, social validity, and treatment efficacy. In the second domain, selecting treatment methods, measurement of the acceptability of various treatment methods taken from Latinx consumers may be correlated with measures of treatment integrity on the part of integral team members (i.e., the fidelity with which they implement a particular protocol) and measures of treatment efficacy and outcome. Finally, in the third domain, communication with consumers, behavior analysts may study the effects of different ways of communicating with Latinx consumers regarding the selection of target behaviors, treatment methods and protocols, informed consent, and rationale on treatment integrity and outcomes. This is especially important in light of studies showing that communication methods affect both comprehension and perceived acceptability of service providers' treatment recommendations (Banks et al., 2018; Becirevic et al., 2016).

Lau (2006) suggested that the merit of any cultural or language adaptations to EBTs should be evaluated in terms of both engagement (i.e., the extent to which integral team members, consumers, and providers actively participate in treatment) and efficacy (i.e., the extent to which treatment is successful in achieving stated objectives). Both of these may be measured objectively in terms of consumer and integral team members' behavior. As such, research on EBT adaptations may be viewed generally as studying relations between consumers' cultural and linguistic contexts, adaptations to EBTs, and the effects of these interactions on dependent variables in the engagement and efficacy domains. 
The evolution of experimental functional analysis (FA) methodology (Iwata et al., 1982/1994) provides an example of how individualized adaptations to EBTs may contribute to treatment efficacy. In its original form, FA methodology consisted of a standardized set of assessment conditions for determining the function(s) of challenging behaviors. All consumers, regardless of their individual circumstances, were exposed to the same general FA conditions. Although this approach was successful in identifying the controlling variables for the challenging behaviors of many individuals, recent research has demonstrated that modifications specifically tailored to the contextual circumstances of individual consumers can enhance the efficacy of the FA in identifying idiosyncratic functions of behavior while retaining its general logic (Jessel et al., 2016; Roscoe et al., 2015; Slaton \& Hanley, 2018). As an example, FAs have been shown to be more effective in identifying the function(s) of escape-maintained problem behavior when the escape condition incorporates ecologically relevant demands characteristic of individuals' natural environments (Roscoe et al., 2009). Kanfer and Saslow (1965, 1969) constructed an outline that included seven different categories to consider when running an FA. Each of these categories brought attention to important variables that can affect consumers' behaviors. One section discussed was the "Analysis of the SocialCultural-Physical Environment." This included an assessment for both the systemic norms of the consumer's natural environment and distinctive life patterns. Findings such as these highlight the practical benefits of taking consumers' unique circumstances into careful consideration when devising assessment and intervention strategies.

The need for cultural and linguistic adaptations to behavior-analytic EBTs can already be observed in recent calls for researchers to begin providing more demographic information about participants in research studies (i.e., Brodhead et al., 2014; Jones et al., 2020; Li et al., 2017). Providing information such as race or ethnicity, gender, and cultural and language background allows for an assessment of the extent to which particular EBTs are effective with individuals from different groups. Brodhead et al. (2014) reported that only 9 of the 103 articles they reviewed from the Journal of Applied Behavior Analysis (JABA) and The Analysis of Verbal Behavior from 2001 to 2011 included information regarding the cultural background of participants, and only one reported information regarding language background. They recommended that authors consider including this information when relevant or making such information available upon request. Li et al. (2017) reviewed 288 articles from five behavior-analytic journals from 2013 to 2015 and found that just 31 of these (10.7\%) included information regarding participants' race or ethnicity. Most recently, Jones et al. (2020) assessed the extent to which publications in JABA for the years 2013-2019 reported the demographic information of participants. They found that age was reported most frequently ( $88 \%$ of studies), followed by diagnosis ( $77 \%$ of studies). All other types of demographic information were reported in less than $75 \%$ of studies. These included gender or sex $(73 \%)$, developmental/functioning level (54\%), education level (33\%), race or ethnicity (7\%), language (4\%), and socioeconomic status (2\%). It is encouraging that the reporting of demographic information is being recommended, but the number of articles providing this information is still relatively low. If researchers began to regularly report this information, it would facilitate meta-analyses of treatment efficacy and social validity across different groups of people, including Latinx consumers and those with LEP. As suggested by Li et al., researchers should also consider explicitly seeking out participants from certain groups to evaluate the effects of EBTs with these individuals and identify potential areas for adaptation. 
Another area in which cultural adaptations to behavior-analytic EBTs are emerging is in language training (Wang et al., 2019). Research in this domain is particularly relevant to Latinx consumers who either live in multilingual households or for whom English is not their primary language. Studies examining the effects of language on discrete-trial instruction (Lang et al., 2011), the acquisition of play skills (Lim \& Charlop, 2018), the recovery of extinguished problem behavior following functional communication training (Neely et al., 2020; Padilla Dalmau et al., 2011), and assessments of behavior function (Rispoli et al., 2011) have demonstrated that the language used during instruction or assessment can have important effects on the outcomes obtained. Multilingual situations present unique challenges for behavior-analytic practitioners, as the language required for the important social interactions taking place in the home may not be the language consumers need to use and respond to in other settings (e.g., school, workplace, community). This raises questions regarding whether language instruction for consumers with language delays should be conducted in only one language, in both languages concurrently, or in different languages in different settings. Treatment decisions regarding these issues also require an analysis of the relative importance of both speaker and listener repertoires in either language in various settings. More research is needed to provide evidence-based guidance to practitioners when making these decisions.

There are many other potential areas in which cultural and language adaptations to behavior-analytic EBTs for Latinx consumers should be evaluated. Barrera et al. (2013) suggested a general five-stage model for identifying the need for and implementing adaptations to EBTs. Briefly, the stages are (a) identifying the need or opportunity for adaptation, (b) involving integral team members in devising adaptations, (c) conducting pilot tests of the adapted EBT, (d) refining and modifying adaptations in light of pilot test results, and (e) conducting a full trial of the finalized adapted EBT and documenting interactions between the adapted EBT and participant characteristics. The authors provided a number of specific recommendations for each stage of this process, and this may serve as a useful template for initiating further behavior-analytic research on adaptations to EBTs for Latinx consumers.

In summary, cultural and language adaptations to EBTs for Latinx consumers may be considered in three general areas: (a) the selection of the behaviors targeted for change, (b) the selection of the methods and procedures used to bring about behavior change, and (c) the way in which decisions regarding both of these are presented verbally to integral team members. The identification of potential modifications to EBTs should be driven by the needs and preferences of Latinx consumers (Barrera, 2013; Fawcett, 1991). The effects of adaptations in any of these areas would ideally be evaluated in terms of both their effects on consumer engagement (i.e., measures of consumers' and integral team members' adherence to and the social validity of adapted EBTs) and efficacy (i.e., measures of the effects of adapted EBTs on target behaviors).

\section{Conclusion}

The field of behavior analysis has historically been characterized by both a commitment to social justice (Ardila Sánchez et al., 2020; Mattaini, 2005; Mattaini \& Rehfeldt, 2020; Skinner, 1948, 1971) and a contextualistic dedication to pragmatic truth criteria 
(i.e., a "what is true is what works" approach for evaluating scientific constructs and the treatment approaches derived from them; L. J. Hayes \& Fryling, 2019; S. C. Hayes et al., 1988; Lattal \& Laipple, 2003). The issues addressed in this article are relevant to concerns in both of these domains. Increasing access to quality behavior-analytic services for Latinx individuals is an issue of equity, but it is also related to treatment efficacy. In other words, addressing barriers to treatment for Latinx consumers through the means considered in this article is bound to increase the efficacy of treatment for these individuals, above and beyond ethical obligations (S. C. Hayes \& Toarmino, 1995). As such, efforts specifically dedicated to increasing cultural diversity in the areas suggested may be seen as a win-win opportunity for behavior analysts and consumers alike. It is hoped that the suggestions offered here serve to identify some of the domains in which such efforts may occur.

Funding No funding to report.

Data availability Not applicable.

\section{Declarations}

Conflict of interest/competing interest We have no known conflicts of interest to disclose.

Code availability Not applicable.

Ethics approval Not applicable.

Consent to participate Not applicable.

Consent for publication Not applicable.

\section{References}

Abraído-Lanza, A. F., Martins, M. C., Shelton, R. C., \& Flórez, K. R. (2015). Breast cancer screening among Dominican Latinas: A closer look at fatalism and other social and cultural factors. Health Education \& Behavior, 42(5), 633-641. https://doi.org/10.1177/1090198115580975

Alcocer, L. F., \& Martinez, A. (2018). Mentoring Hispanic students: Literature review. Journal of Hispanic Higher Education, 17(4), 393-401. https://doi.org/10.1177/1538192717705700

Alegría, M., Canino, G., Shrout, P. E., Woo, M., Duan, N., Vila, D., Torres, M., Chen, C., \& Meng, X. (2008). Prevalence of mental illness in immigrant and non-immigrant U.S. Latino groups. American Journal of Psychiatry, 165(3), 359-369. https://doi.org/10.1176/appi.ajp.2007.07040704

Alegría, M., Fukuda, M., Markle, S. L., \& NeMoyer, A. (2019). Mentoring future researchers: Advice and considerations. American Journal of Orthopsychiatry, 89(3), 329-336. https://doi.org/10.1037/ ort0000416

Alegría, M., \& McGuire, T. (2003). Rethinking a universal framework in the psychiatric symptom-disorder relationship. Journal of Health and Social Behavior, 44(3), 257-274. https://doi.org/10.2307/1519778

American Psychological Association. (2002). Guidelines and principles for accreditation.

Anastasia, E. A., \& Bridges, A. J. (2015). Understanding service utilization disparities and depression in Latinos: The role of fatalismo. Journal of Immigrant and Minority Health, 17(6), 1758-1764. https://doi. org/10.1007/s10903-015-0196-y 
Añez, L. M., Paris Jr., M., Bedregal, L. E., Davidson, L., \& Grilo, C. M. (2005). Application of cultural constructs in the care of first generation Latino clients in a community mental health setting. Journal of Psychiatric Practice, 11(4), 221-230. https://doi.org/10.1097/00131746-200507000-00002

Angell, A. M., Frank, G., \& Solomon, O. (2016). Latino families' experiences with autism services: Disparities, capabilities, and occupational justice. OTJR: Occupation, Participation, and Health, 36(4), 195-203. https://doi.org/10.1177/1539449216666062

Ardila Sánchez, J. G., Cihon, T. M., Malott, M. E., Mattaini, M. A., Rakos, R. F., Rehfeldt, R. A., Richling, S. M., Roose, K. M., Seniuk, H. A., \& Watson-Thompson, J. (2020). Collective editorial: Ten guidelines for strategic social action. Behavior and Social Issues, 29, 1-16. https://doi.org/10.1007/s42822-020-00038-8

August, K. J., Nguyen, H., Ngo-Metzger, Q., \& Sorkin, D. H. (2011). Language concordance and patientphysician communication regarding mental health needs. Journal of the American Geriatrics Society, 59(12), 2356-2362. https://doi.org/10.1111/j.1532-5415.2011.03717

Baer, D. M., Wolf, M. M., \& Risley, T. R. (1968). Some current dimensions of applied behavior analysis. Journal of Applied Behavior Analysis, 1(1), 91-97. https://doi.org/10.1901/jaba.1968.1-91

Baer, D. M., Wolf, M. M., \& Risley, T. R. (1987). Some still-current dimensions of applied behavior analysis. Journal of Applied Behavior Analysis, 20(4), 313-327. https://doi.org/10.1901/jaba.1987.20-313

Banks, B. M., Shriver, M. D., Chadwell, M. R., \& Allen, K. D. (2018). An examination of behavioral treatment wording on acceptability and understanding. Behavioral Interventions, 33(3), 260-270. https:// doi.org/10.1002/bin.1521

Barrera, M., Castro, F. G., Strycker, L. A., \& Toobert, D. J. (2013). Cultural adaptations of behavioral health interventions: A progress report. Journal of Consulting and Clinical Psychology, 81(2), 196-205. https:// doi.org/10.1037/a0027085

Beaulieu, L., Addington, J., \& Almeida, D. (2019). Behavior analysts' training and practices regarding cultural diversity: The case for culturally competent care. Behavior Analysis in Practice, 12(3), 557-575. https:// doi.org/10.1007/s40617-018-00313-6

Becerra, D., Androff, D., Messing, J. T., Castillo, J., \& Cimino, A. (2015). Linguistic acculturation and perceptions of quality, access, and discrimination in health care among Latinos in the United States. Social Work in Health Care, 54(2), 134-157. https://doi.org/10.1080/00981389.2014.982267

Becirevic, A., Critchfield, T. S., \& Reed, D. D. (2016). On the social acceptability of behavior-analytic terms: Crowdsourced comparisons of lay and technical language. The Behavior Analyst, 39(2), 305-317. https:// doi.org/10.1007/s40614-016-0067-4

Beene, N. (2019). Letter to the editor: One perspective on diversity in ABA. Behavior Analysis in Practice, 12(4), 899-901. https://doi.org/10.1007/s40617-019-00378-x

Behavior Analyst Certification Board. (2014). Professional and ethical compliance code for behavior analysts. Author.

Behavior Analyst Certification Board. (2016). Professional and ethical compliance code for behavior analysts. Retrieved from https:/www.bacb.com/wpcontent/uploads/2017/09/170706-compliance-codeenglish.pdf

Behavior Analyst Certification Board. (2017). BCBA/BCaBA task list (5th ed.). Author.

Behavior Analyst Certification Board. (2020a). Ethics code for behavior analysts. Author.

Behavior Analyst Certification Board. (2020b). BACB certificant data. https://www.bacb.com/bacbcertificant-data/

Bensimon, E. M., Dowd, A. C., \& Witham, K. (2016). Five principles for enacting equity by design. Diversity \& Democracy, 19(1), 1-8.

Bermudez, I. L., \& Rios, J. D. (2020). Latinos in applied behavior analysis: We have a long way to go. In B. M. Conners \& S. T. Capell (Eds.), Multiculturalism and diversity in applied behavior analysis: Bridging theory and application (pp. 47-56). Routledge.

Bernal, G., \& Adames, C. (2017). Cultural adaptations: Conceptual, ethical, contextual, and methodological issues for working with ethnocultural and majority-world populations. Prevention Science, 18(6), 681688. https://doi.org/10.1007/s11121-017-0806-0

Bernal, G., Jiménez-Chafey, M. I., \& Domenech Rodríguez, M. M. (2009). Cultural adaptation of treatments: A resource for considering culture in evidence-based practice. Professional Psychology: Research and Practice, 40(4), 361-368. https://doi.org/10.1037/a0016401

Bhalla, N. (2019). Strategies to improve equity in faculty hiring. Molecular Biology of the Cell, 30(22), 2744 2749. https://doi.org/10.1091/mbc.E19-08-0476

Bhattarai, J. J., Bentley, J., Morean, W., Wegener, S. T., \& Pollack Porter, K. M. (2020). Promoting equity at the population level: Putting the foundational principles into practice through disability advocacy. Rehabilitation Psychology, 65(2), 87-100. https://doi.org/10.1037/rep0000321 
Bishop-Fitzpatrick, L., \& Kind, A. J. H. (2017). A scoping review of health disparities in autism spectrum disorder. Journal of Autism and Developmental Disorders, 47(11), 3380-3391. https://doi.org/10.1007/ s10803-017-3251-9

Brodhead, M. T. (2019). Culture always matters: Some thoughts on Rosenberg and Schwartz. Behavior Analysis in Practice, 12(4), 826-830. https://doi.org/10.1007/s40617-019-00351-8

Brodhead, M. T., Cox, D. J., \& Quigley, S. P. (2018). Practical ethics for effective treatment of autism spectrum disorder. Elsevier.

Brodhead, M. T., Durán, L., \& Bloom, S. E. (2014). Cultural and linguistic diversity in recent verbal behavior research on individuals with disabilities: A review and implications for research and practice. The Analysis of Verbal Behavior, 30(1), 75-86. https://doi.org/10.1007/s40616-014-0009-8

Brodhead, M. T., \& Higbee, T. S. (2012). Teaching and maintaining ethical behavior in a professional organization. Behavior Analysis in Practice, 5(2), 82-88. https://doi.org/10.1007/BF03391827

Buzhardt, J., Rusinko, L., Heitzman-Powell, L., Trevino-Maack, S., \& McGrath, A. (2016). Exploratory evaluation and initial adaptation of a parent training program for Hispanic families of children with autism. Family Process, 55(1), 107-122. https://doi.org/10.1111/famp.12146

Cabassa, L. J., Molina, G. B., \& Baron, M. (2012). Depression fotonovela: Development of a depression literacy tool for Latinos with limited English proficiency. Health Promotion Practice, 13(6), 747-754. https://doi.org/10.1177/1524839910367578

Cabral, R. R., \& Smith, T. B. (2011). Racial/ethnic matching of clients and therapists in mental health services: A meta-analytic review of preferences, perceptions, and outcomes. Journal of Counseling Psychology, 58(4), 537-554. https://doi.org/10.1037/a0025266

Callahan, J. L., Smotherman, J. M., Dziurzynski, K. E., Love, P. K., Kilmer, E. D., Niemann, Y. F., \& Ruggero, C. J. (2018). Diversity in the professional psychology training-to-workforce pipeline: Results from doctoral psychology student population data. Training and Education in Professional Psychology, 12(4), 273-285. https://doi.org/10.1037/tep0000203

Capell, S. T., \& Sevon, M. A. (2020). Applied behavior analysis within the African American community. In B. M. Conners \& S. T. Capell (Eds.), Multiculturalism and diversity in applied behavior analysis: Bridging theory and application (pp. 29-46). Routledge.

Cauce, A. M., \& Domenech-Rodríguez, M. (2002). Latino families: Myths and realities. In J. M. Contreras, K. A. Kerns, \& A. M. Neal-Barnett (Eds.), Latino children and families in the United States (pp. 5-25). Praeger.

Centers for Disease Control and Prevention. (2021). Health equity considerations and racial and ethnic minority groups. https:/www.cdc.gov/coronavirus/2019-ncov/community/health-equity/race-ethnicity. html\#anchor_1595551060069

Chapa, T. (2004). Mental health services in primary care settings for racial and ethnic minority populations. Office of Minority Health. https://minorityhealth.hhs.gov/Assets/pdf/Checked/1/Mental_Health_ Services_in_Primary_Care_Settings_for_Racial2004.pdf

Chen, J., \& Vargas-Bustamante, A. (2011). Estimating the effects of immigration status on mental health care utilizations in the United States. Journal of Immigrant and Minority Health, 13(4), 671-680. https://doi. org/10.1007/s10903-011-9445-X

Cirincione-Ulezi, N. (2020). Black women and barriers to leadership in ABA. Behavior Analysis in Practice, 13, 719-724. https://doi.org/10.1007/s40617-020-00444-9

Claes, C., Van Hove, G., Vandevelde, S., van Look, J., \& Schalock, R. (2010). Person-centered planning: Analysis of research and effectiveness. Intellectual and Developmental Disabilities, 48(6), 432-453. https://doi.org/10.1352/1934-9556-48.6.432

Common, E. A., \& Lane, K. L. (2017). Social validity assessment. In J. K. Luiselli (Ed.), Applied behavior analysis advanced guidebook: A manual for professional practice (pp. 73-92). Elsevier.

Conners, B., Johnson, A., Duarte, J., Murriky, R., \& Marks, K. (2019). Future directions of training and fieldwork in diversity issues in applied behavior analysis. Behavior Analysis in Practice, 12(4), 767-776. https://doi.org/10.1007/s40617-019-00349-2

Crosby, F. J., Iyer, A., Clayton, S., \& Downing, R. A. (2003). Affirmative action: Psychological data and the policy debates. The American Psychologist, 58(2), 93-115. https://doi.org/10.1037/0003-066X.58.2.93

Dahne, J., Collado, A., Lejuez, C. W., Risco, C. M., Diaz, V. A., Coles, L., Kustanowitz, J., Zvolensky, M. J., \& Carpenter, M. J. (2019). Pilot randomized controlled trial of a Spanish-language behavioral activation mobile app (¡Aptívate!) for the treatment of depressive symptoms among United States Latinx adults with limited English proficiency. Journal of Affective Disorders, 250, 210-217. https://doi.org/10.1016/j.jad. 2019.03.009 
Dennison, A., Lund, E. M., Brodhead, M. T., Mejia, L., Armenta, A., \& Leal, J. (2019). Delivering homesupported applied behavior analysis therapies to culturally and linguistically diverse families. Behavior Analysis in Practice, 12(4), 887-898. https://doi.org/10.1007/s40617-019-00374-1

Domenech Rodríguez, M. M., Baumann, A. A., \& Schwartz, A. L. (2011). Cultural adaptation of an evidence based intervention: From theory to practice in a Latino/a community context. American Journal of Community Psychology, 47(1-2), 170-186. https://doi.org/10.1007/s10464-010-9371-4

Dumas-Hines, F. A., Cochran, L. L., \& Williams, E. U. (2001). Promoting diversity: Recommendations for recruitment and retention of minorities in higher education. College Student Journal, 33, 90-196.

Ecklund, E. H., \& Long, E. (2011). Scientists and spirituality. Sociology of Religion, 72(3), 253-274. https:// doi.org/10.1093/socrel/srr003

Espinosa de los Monteros, K., \& Gallo, L. C. (2011). The relevance of fatalism in the study of Latinas' cancer screening behavior: A systematic review of the literature. International Journal of Behavioral Medicine, 18(4), 310-318. https://doi.org/10.1007/s12529-010-9119-4

Esquierdo-Leal, J. L., \& Houmanfar, R. A. (2021). Creating Inclusive and Equitable Cultural Practices by Linking Leadership to Systemic Change. Behavior Analysis in Practice, 14(2), 1-512. https://doi.org/10. 1007/s40617-020-00519-7

Falicov, C. J. (1998). Latino families in therapy: A guide to multicultural practice. Guilford Press.

Fawcett, S. B. (1991). Some values guiding community research and action. Journal of Applied Behavior Analysis, 24(4), 621-636. https://doi.org/10.1901/jaba.1991.24-621

Ferguson, W. J., \& Candib, L. M. (2002). Culture, language, and the doctor-patient relationship. Family Medicine, 34(5), 353-361.

Fernandez, A., Schillinger, D., Warton, E. M., Adler, N., Moffet, H. H., Schenker, Y., Salgado, M. V., Ahmed, A., \& Karter, A. J. (2011). Language barriers, physician-patient language concordance, and glycemic control among insured Latinos with diabetes: The diabetes study of Northern California. Journal of General Internal Medicine, 26(2), 170-176.

Finkelstein, M. J., Conley, V. M., \& Schuster, J. H. (2016). Taking the measure of faculty diversity. TIAA Institute, Advancing Higher Education. Retrieved from https:/www.tiaainstitute.org/sites/default/files/ presentations/2017-02/taking_the_measure_of_faculty_diversity.pdf

Fisher-Borne, M., Cain, J. M., \& Martin, S. L. (2015). From mastery to accountability: Cultural humility as an alternative to cultural competence. Social Work Education, 34(2), 165-181. https://doi.org/10.1080/ 02615479.2014 .977244

Flores, G. (2000). Culture and the patient-physician relationship: Achieving cultural competency in health care. Journal of Pediatrics, 136(1), 14-23. https://doi.org/10.1016/s0022-3476(00)90043-x

Flores, G., \& Committee on Pediatric Research. (2010). Racial and ethnic disparities in the health and health care of children. Pediatrics, 125(4), e979.

Flórez, K. R., Aguirre, A. N., Viladrich, A., Céspedes, A., De La Cruz, A. A., \& Abraído-Lanza, A. F. (2009). Fatalism or destiny? A qualitative study and interpretative framework on Dominican women's breast cancer beliefs. Journal of Immigrant and Minority Health, 11(4), 291-301. https://doi.org/10.1007/ s10903-008-9118-6

Fong, E. H. (2020). Standards for culturally sensitive practice of applied behavior analysis. In B. M. Conners \& S. T. Capell (Eds.), Multiculturalism and diversity in applied behavior analysis: Bridging theory and application (pp. 19-27). Routledge.

Fong, E. H., Catagnus, R. M., Brodhead, M. T., Quigley, S., \& Field, S. (2016). Developing the cultural awareness skills of behavior analysts. Behavior Analysis in Practice, 9(1), 84-94. https://doi.org/10.1007/ s40617-016-0111-6

Fong, E. H., Ficklin, S., \& Lee, H. Y. (2017). Increasing cultural understanding and diversity in applied behavior analysis. Behavior Analysis: Research and Practice, 17(2), 103-113. https://doi.org/10.1037/ bar0000076

Fong, E. H., Jarmuz-Smith, S., Dogan, R., Serna, R., \& Woolery, K. (2015). The behavior analyst and cultural competency. REDCap.

Fong, E. H., \& Tanaka, S. (2013). Multicultural alliance of behavior analysis standards for cultural competence in behavior analysis. International Journal of Behavioral and Consultation Therapy, 8(2), 17-19. https://doi.org/10.1037/h0100970

Frederick, J. K., Rogers, V. R., \& Raabe, G. R. (2021). Commitment, collaboration, and problem resolution to promote and sustain access to multifaceted applied behavior-analytic services utilizing telepractice. Behavior Analysis in Practice, 1-23. https://doi.org/10.1007/s40617-020-00550-8

Fries-Britt, S. L., Rowan-Kenyon, H. T., Perna, L. W., Milem, J. F., \& Howard, D. G. (2011). Underrepresentation in the academy and the institutional climate for faculty diversity. Journal of the Professoriate, 5(1), 1-34. 
Garcia-Preto, N. (2005). Latino families: An overview. In M. McGoldrick, J. Giordano, \& N. Garcia-Preto (Eds.), Ethnicity and family therapy (pp. 153-165). The Guilford Press.

Griffin, K. A. (2019). Redoubling our efforts: How institutions can affect faculty diversity. American Council on Education. https://www.equityinhighered.org/resources/ideas-and-insights/redoubling-our-effortshow-institutions-can-affect-faculty-diversity/

Guilamo-Ramos, V., Dittus, P., Jaccard, J., Johansson, M., Bouris, A., \& Acosta, N. (2007). Parenting Practices among Dominican and Puerto Rican Mothers. Social Work (New York), 52(1), 17-30. https:// doi.org/10.1093/sw/52.1.17

Hansen, M. C., \& Aranda, M. P. (2012). Sociocultural influences on mental health service use by Latino older adults for emotional distress: Exploring the mediating and moderating role of informal social support. Social Science \& Medicine, 75(12), 2134-2142. https://doi.org/10.1016/j.socscimed.2012.06.029

Harwood, R. L., Leyendecker, B., Carlson, V., Asencio, M., \& Miller, A. (2002). Parenting among Latino families in the US. In M. H. Bornstein (Ed.), Handbook of parenting: Vol. 4. Social conditions and applied parenting (2nd ed., pp. 21-46). Lawrence Erlbaum.

Hayes, L. J., \& Fryling, M. J. (2019). Functional and descriptive contextualism. Journal of Contextual Behavioral Science, 14, 119-126. https://doi.org/10.1016/j.jcbs.2019.09.002

Hayes, S. C., Barnes-Holmes, D., \& Roche, B. (Eds.). (2001). Relational frame theory: A post-Skinnerian account of human language and cognition. Kluwer Academic/Plenum Publishers.

Hayes, S. C., Hayes, L. J., \& Reese, H. W. (1988). Finding the philosophical core: A review of Stephen C. Pepper's World hypotheses: A study in evidence. Journal of the Experimental Analysis of Behavior, 50(1), 97-111.

Hayes, S. C., \& Toarmino, D. (1995). If behavioral principles are generally applicable, why is it necessary to understand cultural diversity? The Behavior Therapist, 18, 21-23.

Hill, C., Corbett, C., \& St. Rose, A. (2010). Why so few? Women in science, technology, engineering, and mathematics. American Association of University Women.

Hines, A. L., Cooper, L. A., \& Shi, L. (2017). Racial and ethnic differences in mental healthcare utilization consistent with potentially effective care: The role of patient preferences. General Hospital Psychiatry, 46, 14-19. https://doi.org/10.1016/j.genhosppsych.2017.02.002

Hinton, A. O., Vue, Z., Termini, C. M., Taylor, B. L., Shuler, H. D., \& McReynolds, M. R. (2020). Mentoring minority trainees. EMBO Reports, 21(10). https://doi.org/10.15252/embr.202051269

Holloway-Friesen, H. (2019). The role of mentoring on Hispanic graduate students' sense of belonging and academic self efficacy. Journal of Hispanic Higher Education, 20(1), 46-58. https://doi.org/10.1177/ 1538192718823716

Institute of Medicine. (2003). Unequal treatment: Confronting racial and ethnic disparities in health care. National Academies Press.

Iwata, B. A., Dorsey, M. F., Slifer, K. J., Bauman, K. E., \& Richman, G. S. (1994). Toward a functional analysis of self-injury. Journal of Applied Behavior Analysis, 27(2), 197-209. https://doi.org/10.1901/ jaba.1994.27-197

Jessel, J., Hanley, G. P., \& Ghaemmaghami, M. (2016). Interview-informed synthesized contingency analyses: Thirty replications and reanalysis. Journal of Applied Behavior Analysis, 49(3), 576-595. https://doi. org/10.1002/jaba.316

Jones, S. H., St. Peter, C. C., \& Ruckle, M. M. (2020). Reporting of demographic variables in the Journal of Applied Behavior Analysis. Journal of Applied Behavior Analysis, 53(3), 1304-1315. https://doi.org/10. 1002/jaba. 722

Kanfer, F. H., \& Saslow, G. (1965). Behavioral analysis: An alternative to diagnostic classification. Archives of General Psychiatry, 12(6), 529-538. https://doi.org/10.1001/archpsyc.1965.01720360001001

Kanfer, F. H., \& Saslow, G. (1969). Behavioral diagnosis. In C. M. Franks (Ed.), Behavior therapy: Appraisal and status (pp. 417-444). McGraw Hill.

Kazdin, A. E. (1977). Assessing the clinical or applied importance of behavior change through social validation. Behavior Modification, 1(4), 427-452. https://doi.org/10.1177/014544557714001

Kleeck, A. V. (1994). Potential cultural bias in training parents as conversational partners with their children who have delays in language development. American Journal of Speech-Language Pathology, 3(1), 6778.

Klinge, C. M. (2015). A conceptual framework for mentoring in a learning organization. Adult Learning, 26(4), 160-166. https://doi.org/10.1177/1045159515594154

Kornack, J., Cernius, A., \& Persicke, A. (2019). The diversity is in the details: Unintentional language discrimination in the practice of applied behavior analysis. Behavior Analysis in Practice, 12(4), 879-886. https://doi.org/10.1007/s40617-019-00377-y 
Kouyoumdjian, H., Zamboanga, B. L., \& Hansen, D. J. (2003). Barriers to community mental health services for Latinos: Treatment considerations. Clinical Psychology, 10(4), 394-422. https://doi.org/10.1093/ clipsy.bpg041

Kuh, G. D. (2012). Excerpt from high-impact educational practices: What they are, who has access to them, and why they matter. Association of American Colleges and Universities, 14(3), 28-29.

Kullgren, J. T. (2003). Restrictions on undocumented immigrants' access to health services: The public health implications of welfare reform. American Journal of Public Health, 93(10), 1630-1633. https://doi.org/ 10.2105/AJPH.93.10.1630

Lagomasino, I. T., Dwight-Johnson, M., Miranda, J., Zhang, L., Liao, D., Duan, N., \& Wells, K. B. (2005). Disparities in depression treatment for Latinos and site of care. Psychiatric Services, 56(12), 1517-1523. https://doi.org/10.1176/appi.ps.56.12.1517

Lang, R., Rispoli, M., Sigafoos, J., Lancioni, G., Andrews, A., \& Ortega, L. (2011). Effects of language of instruction on response accuracy and challenging behavior in a child with autism. Journal of Behavioral Education, 20(4), 252-259. https://doi.org/10.1007/s10864-011-9130-0

Larson, A. L., An, Z. G., Wood, C., Uchikoshi, Y., Cycyk, L. M., Scheffner Hammer, C., Escobar, K., \& Roberts, K. (2020). Social validity in early language interventions for dual language learners: A systematic review of the literature. Topics in Early Childhood Special Education, 40(1), 39-51. https:// doi.org/10.1177/0271121419901289

Latino Association for Behavior Analysis. (2019). Our Mission. https://www.laba-aba.com/

Lattal, K. A., \& Laipple, J. (2003). Pragmatism and behavior analysis. In K. A. Lattal \& P. N. Chase (Eds.), Behavior theory and philosophy (pp. 41-61). Kluwer/Plenum. https://doi.org/10.1007/978-1-4757-459003

Lau, A. S. (2006). Making the case for selective and directed cultural adaptations of evidence-based treatments: Examples from parent training. Clinical Psychology, 13(4), 295-310. https://doi.org/10. 1111/j.1468-2850.2006.00042.x

Li, A., Wallace, L., Ehrhardt, K. E., \& Poling, A. (2017). Reporting participant characteristics in intervention articles published in five behavior-analytic journals, 2013-2015. Behavior Analysis: Research and Practice, 17(1), 84-91. https://doi.org/10.1037/bar0000071

Lim, N., \& Charlop, M. H. (2018). Effects of English versus heritage language on play in bilingually exposed children with autism spectrum disorder. Behavioral Interventions, 33(4), 339-351. https://doi.org/10. 1002/bin. 1644

Limited English Proficiency (n.d.). Commonly Asked Questions and Answers Regarding Limited English Proficient (LEP) Individuals. http://www.lep.gov/faqs/042511 Q\&A LEP General.pdf.

Litvak, S. G., \& Rue, H. (2020). Creating a culturally competent clinical practice. In B. M. Conners \& S. T. Capell (Eds.), Multiculturalism and diversity in applied behavior analysis: Bridging theory and application (pp. 123-136). Routledge.

Llamas, J. D., Nguyen, K., \& Tran, A. G. T. T. (2019). The case for greater faculty diversity: Examining the educational impacts of student-faculty racial/ethnic match. Race Ethnicity and Education, 1-17. https:// doi.org/10.1080/13613324.2019.1679759

Lopez, C., Bergren, M. D., \& Painter, S. G. (2008). Latino disparities in child mental health services. Journal of Child and Adolescent Psychiatric Nursing, 21(3), 137-145. https://doi.org/10.1111/j.1744-6171.2008. 00146.x

López, G., \& Gonzalez-Barrera, A. (2016). Afro-Latino: A deeply rooted identity among U.S. Hispanics. Pew Research Center. https:/www.pewresearch.org/fact-tank/2016/03/01/afro-latino-a-deeply-rooted-identityamong-u-s-hispanics/

Macias Gil, R., Marcelin, J. R., Zuniga-Blanco, B., Marquez, C., Mathew, T., \& Piggott, D. A. (2020). COVID-19 pandemic: Disparate health impact on the Hispanic/Latinx population in the United States. Journal of Infectious Diseases, 222(10), 1592-1595. https://doi.org/10.1093/infdis/jiaa474

Magaña, D. (2020). Local voices on health care communication issues and insights on Latino cultural constructs. Hispanic Journal of Behavioral Sciences, 42(3), 300-323. https://doi.org/10.1177/ 0739986320927387

Magaña, S., Lopez, K., Aguinaga, A., \& Morton, H. (2013). Access to diagnosis and treatment services among Latino children with autism spectrum disorders. Intellectual and Developmental Disabilities, 51(3), 141153. https://doi.org/10.1352/1934-9556-51.3.141

Makino, K., \& Oliver, C. (2019). Developing diverse leadership pipelines: A requirement for 21st century success. Organizational Development Review, 51(1), 4-10.

Marschke, R., Laursen, S., Nielsen, J. M., \& Dunn-Rankin, P. (2007). Demographic inertia revisited: An immodest proposal to achieve equitable gender representation among faculty in higher education. Journal of Higher Education, 78(1), 1-26. https://doi.org/10.1353/jhe.2007.0003 
Masuda, A. (2014). Mindfulness and acceptance in multicultural competency: A contextual approach to sociocultural diversity in theory and practice. Context Press.

Mattaini, M. A. (2005). Mapping practice: Assessment, context, and social justice. In S. A. Kirk (Ed.), Mental disorders in the social environment: Critical perspectives (pp. 62-82). Columbia University Press.

Mattaini, M. A., \& Rehfeldt, R. A. (2020). Editorial: Rendezvous with truth and discovery. Behavior and Social Issues, 29, 1-14. https://doi.org/10.1007/s42822-020-00034-y

Mendez, J. L., \& Westerberg, D. (2012). Implementation of a culturally adapted treatment to reduce barriers for Latino parents. Cultural Diversity \& Ethnic Minority Psychology, 18(4), 363-372. https://doi.org/10. $1037 / \mathrm{a} 0029436$

Miller, K. L., Cruz, A. R., \& Ala'i-Rosales, S. (2019). Inherent tensions and possibilities: Behavior analysis and cultural responsiveness. Behavior and Social Issues, 28(1), 16-36. https://doi.org/10.1007/s42822019-00013-y

Morales, L. S., Cunningham, W. E., Brown, J. A., Liu, H., \& Hays, R. D. (1999). Are Latinos less satisfied with communication by health care providers? Journal of General Internal Medicine, 14(7), 409-417. https://doi.org/10.1046/j.1525-1497.1999.06198.x

Motel, S., \& Patten, E. (2012). The 10 largest Hispanic origin groups: Characteristics, rankings, top counties. Pew Research Center. Retrieved from https://www.pewresearch.org/hispanic/2012/06/27/the-10-largesthispanic-origin-groups-characteristicsrankings-top-counties/\#: :text=Overall\%2C\%20the\%2010\% 20largest\%20Hispanic,of\%20the\%20U.S.\%20Hispanic\%20population

Najdowski, A. C., Gharapetian, L., \& Jewett, V. (2021). Toward the development of antiracist and multicultural graduate training programs in behavior analysis. Behavior Analysis in Practice, 14, 462-477. https:// doi.org/10.1007/s40617-020-00504-0

Neely, L., Graber, J., Kunnavatana, S., \& Cantrell, K. (2020). Impact of language on behavior treatment outcomes. Journal of Applied Behavior Analysis, 53(2), 796-810. https://doi.org/10.1002/jaba.626

Noe-Bustamante, L., Mora, L., \& Lopez, M. H. (2020). About one-in-four U.S. Hispanics have heard of Latinx, but just 3\% use it. Pew Research Center.

O’Meara, K., Culpepper, D., \& Templeton, L. L. (2020). Nudging toward diversity: Applying behavioral design to faculty hiring. Review of Educational Research, 90(3), 311-348. https://doi.org/10.3102/ 0034654320914742

Ornelas, I. J., \& Perreira, K. M. (2011). The role of migration in the development of depressive symptoms among Latino immigrant parents in the USA. Social Science \& Medicine, 73(8), 1169-1177. https://doi. org/10.1016/j.socscimed.2011.07.002

Padilla Dalmau, Y. C., Wacker, D. P., Harding, J. W., Berg, W. K., Schieltz, K. M., Lee, J. F., Breznican, G. P., \& Kramer, A. R. (2011). A preliminary evaluation of functional communication training effectiveness and language preference when Spanish and English are manipulated. Journal of Behavioral Education, 20(4), 233-251. https://doi.org/10.1007/s10864-011-9131-z

Paniagua, F. A. (1998). Assessing and treating culturally diverse clients: A practical guide (2nd ed.). SAGE.

Park, E.-Y., \& Blair, K.-S. C. (2019). Social Validity Assessment in Behavior Interventions for Young Children: A Systematic Review. Topics in Early Childhood Special Education, 39(3), 156-169. https:// doi.org/10.1177/0271121419860195

Parsai, M., Voisine, S., Marsiglia, F. F., Kulis, S., \& Nieri, T. (2009). The protective and risk effects of parents and peers on substance use, attitudes, and behaviors of Mexican and Mexican American female and male adolescents. Youth \& Society, 40(3), 353-376. https://doi.org/10.1177/0044118X08318117

Patel, V. (2015). Dearth of Black Ph.D. recipients will complicate efforts to diversify faculty. The Chronicle of Higher Education. https://www.chronicle.com/article/Dearth-of-Black-PhD/234469

Peters, M. L., Sawyer, C. B., Guzmán, M. R., \& Graziani, C. (2014). Supporting the development of Latino bilingual mental health professionals. Journal of Hispanic Higher Education, 13(1), 15-31. https://doi. org/10.1177/1538192713514611

Rastogi, M., Massey-Hastings, N., \& Wieling, E. (2012). Barriers to seeking mental health services in the Latino/a community: A qualitative analysis. Journal of Systemic Therapies, 31(4), 1-17. https://doi.org/ 10.1521/jsyt.2012.31.4.1

Rispoli, M., O’Reilly, M., Lang, R., Sigafoos, J., Mulloy, A., Aguilar, J., \& Singer, G. (2011). Effects of language of implementation on functional analysis outcomes. Journal of Behavioral Education, 20(4), 224-232. https://doi.org/10.1007/s10864-011-9128-7

Rogers, M. R., \& Molina, L. E. (2006). Exemplary efforts in psychology to recruit and retain graduate students of color. The American Psychologist, 61(2), 143-156. https://doi.org/10.1037/0003-066X.61.2.143

Rosales, R., \& Calvo, R. (2017). "Si dios quiere": Fatalismo and use of mental health services among Latinos with a history of depression. Social Work in Health Care, 56(8), 748-764. https://doi.org/10.1080/ 00981389.2017.1339760 
Rosales, R., Leon, A., Serna, R. W., Maslin, M., Arevalo, A., \& Curtin, C. (2021). A first look at applied behavior analysis service delivery to Latino American families raising a child with autism spectrum disorder. Behavior Analysis in Practice, 1-10. https://doi.org/10.1007/s40617-021-00572-w

Roscoe, E. M., Rooker, G. W., Pence, S. T., Longworth, L. J., \& Zarcone, J. (2009). Assessing the utility of a demand assessment for functional analysis. Journal of Applied Behavior Analysis, 42, 819-825. https:// doi.org/10.1901/jaba.2009.42-819

Roscoe, E. M., Schlichenmeyer, K. J., \& Dube, W. V. (2015). Functional analysis of problem behavior: A systematic approach for identifying idiosyncratic variables. Journal of Applied Behavior Analysis, 48(2), 289-314. https://doi.org/10.1002/jaba.201

Rosenberg, N. E., \& Schwartz, I. S. (2019). Guidance or compliance: What makes an ethical behavior analyst? Behavior Analysis in Practice, 12(2), 473-482. https://doi.org/10.1007/s40617-018-00287-5

Santiago-Rivera, A. (2003). Latinos values and family transitions: Practical considerations for counseling. Counseling and Human Development, 35(6), 1-12.

Schalock, R., Verdugo, M., Bonham, G., Fantova, F., \& van Loon, J. (2008). Enhancing personal outcomes: Organizational strategies, guidelines, and examples. Journal of Policy and Practice in Intellectual Disabilities, 5(4), 276-285. https://doi.org/10.1111/j.1741-1130.2007.00135.x

Scharrón-del Río, M. R., \& Aja, A. A. (2020). Latinx: Inclusive language as liberation praxis. Journal of Latinx Psychology, 8(1), 7-20. https://doi.org/10.1037/lat0000140

Schwab, T., Meyer, J., \& Merrell, R. (1994). Measuring attitudes and health beliefs among Mexican Americans with diabetes. The Diabetes Educator, 20(3), 221-227. https://doi.org/10.1177/ 014572179402000308

Sensoy, Ö., \& DiAngelo, R. (2017). "We are all for diversity, but": How faculty hiring committees reproduce Whiteness and practical suggestions for how they can change. Harvard Educational Review, 87(4), 557580. https://doi.org/10.17763/1943-5045-87.4.557

Skinner, B. F. (1948). Walden two. Macmillan.

Skinner, B. F. (1971). Beyond freedom and dignity. Knopf.

Slaton, J. D., \& Hanley, G. P. (2018). Nature and scope of synthesis in functional analysis and treatment of problem behavior. Journal of Applied Behavior Analysis, 51(4), 943-973. https://doi.org/10.1002/jaba. 498

Smith, T. B., Domenech-Rodríguez, M., \& Bernal, G. (2011). Culture. Journal of Clinical Psychology, 67, 166-175. https://doi.org/10.1002/jclp.20757

Smith, D. G., Turner, C. S., Osei-Kofi, N., \& Richards, S. (2004). Interrupting the usual: Successful strategies for hiring diverse faculty. Journal of Higher Education, 75(2), 133-160. https://doi.org/10.1080/ 00221546.2004.11778900

Snowden, L., Masland, M., Ma, Y., \& Ciemens, E. (2006). Strategies to improve minority access to public mental health services in California: Description and preliminary evaluation. Journal of Community Psychology, 34(2), 225-235. https://doi.org/10.1002/jcop.20092

Steinmetz, K. (2018). Why "Latinx" is succeeding while other gender-neutral terms fail to catch on. Time. https:/time.com/5191804/latinx-definition-meaning-latino-hispanic-gender-neutral/

Strain, P. S., Barton, E. E., \& Dunlap, G. (2012). Lessons learned about the utility of social validity. Education \& Treatment of Children, 35(2), 183-200. https://doi.org/10.1353/etc.2012.0007

Sue, D. W., \& Sue, D. (2016). Counseling the culturally diverse: Theory and practice (7th ed.). John Wiley \& Sons.

Szabo, T. G. (2020). Equity and diversity in behavior analysis: Lessons from Skinner (1945). Behavior Analysis in Practice, 13(2), 375-386. https://doi.org/10.1007/s40617-020-00414-1

Tervalon, M., \& Murray-Garcia, J. (1998). Cultural humility versus cultural competence: A critical distinction in defining physician training outcomes in multicultural education. Journal of Health Care for the Poor and Underserved, 9(2), 117-125. https://doi.org/10.1353/hpu.2010.0233

Torres, L., \& Rollock, D. (2004). Acculturative distress among Hispanics: The role of acculturation, coping, and intercultural competence. Journal of Multicultural Counseling and Development, 32(3), 155-167. https://doi.org/10.1002/j.2161-1912.2004.tb00368.x

University of Michigan. (2020). Diversity recruitment weekend. Retrieved from https://lsa.umich.edu/psych/ diversity/diversityrecruitment-weekend.html

U.S. Census Bureau. (2018). Hispanic or Latino by type, 2018. Retrieved from https://www.census.gov/ quickfacts/fact/table/US/PST0452

U.S. Department of Education. (2016). Race and ethnicity of higher education faculty. American Council on Education. https:/www.equityinhighered.org/indicators/postsecondary-faculty-and-staff/race-andethnicity-of-higher-education-faculty/ 
Valenzuela, J., Crosby, L. E., \& Harrison, R. R. (2020). Commentary: Reflections on the COVID-19 pandemic and health disparities in pediatric psychology. Journal of Pediatric Psychology, 45, 839-841. https://doi.org/10.1093/jpepsy/jsaa063

Vespa, J., Armstrong, D. M., \& Medina, L. (2020). Demographic turning points for the United States: Population projections for 2020 to 2060. U.S. Census Bureau. https://www.census.gov/ library/publications/2020/demo/p25-1144.html

Wang, Y., Kang, S., Ramirez, J., \& Tarbox, J. (2019). Multilingual diversity in the field of applied behavior analysis and autism: A brief review and discussion of future directions. Behavior Analysis in Practice, 12(4), 795-804. https://doi.org/10.1007/s40617-019-00382-1

Weinstein, J. H., Wilson, K. G., Drake, C. E., \& Kellum, K. K. (2008). A relational frame theory contribution to social categorization. Behavior and Social Issues, 17(1), 40-65. https://doi.org/10.5210/bsi.v17i1.406

Wolf, M. M. (1978). Social validity: The case for subjective measurement or how applied behavior analysis is finding its heart. Journal of Applied Behavior Analysis, 11(2), 203-214. https://doi.org/10. 1901/ jaba.1978.11-203.

Wright, P. I. (2019). Cultural humility in the practice of applied behavior analysis. Behavior Analysis in Practice, 12(4), 805-809. https://doi.org/10.1007/s40617-019-00343-8

Zarcone, J., Brodhead, M., \& Tarbox, J. (2019). Beyond a call to action: An introduction to the special issue on diversity and equity in the practice of behavior analysis. Behavior Analysis in Practice, 12(4), 741742. https://doi.org/10.1007/s40617-019-00390-1

Zong, J., \& Batalova, J. (2015). The limited English proficient population in the United States in 2013. Migration Policy Institute. https://www.migrationpolicy.org/article/limited-english-proficient-populationunited-states-2013

Zuckerman, K. E., Lindly, O. J., Reyes, N. M., Chavez, A. E., Macias, K., Smith, K. N., \& Reynolds, A. (2017). Disparities in diagnosis and treatment of autism in Latino and non-Latino White families. Pediatrics, 139(5), e20163010. https://doi.org/10.1542/peds.2016-3010 